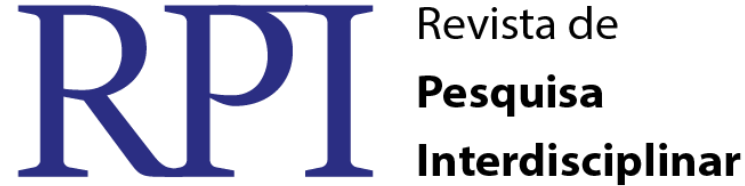

\section{AS CONTRIBUIÇÕES ACERCA DA RELAÇÃO ESCOLA, FAMÍLIA E SOCIEDADE NO PROCESSO DE FORMAÇÃO ESCOLAR}

\author{
Karla Roberta Dantas Alves - UAE/CFP/UFCG ${ }^{1}$ \\ Josefa Laureana de Sousa Andrade - UAE/CFP/UFCG ${ }^{2}$
}

\begin{abstract}
RESUMO
Com base na leitura e discussão dos textos de autores como: Antunes (2007), Borges e Fontoura (2010), Matsuoka (2013), Nogueira (2010), Nóvoa (1996), Szymanski (2004), que nos favoreceram uma reflexão acerca da relação escola, família e sociedade na perspectiva de pautar essas relações como norteadora da construção da autonomia enquanto formação escolar e caminho percorrido até as universidades. Na visão da família, como a primeira instituição social, na qual a criança está inserida, é perceptível que os alunos que tem um maior acompanhamento familiar demonstram um avanço no desempenho escolar e, por conseguinte, o ingresso e permanência nas universidades, o que contribui para uma formação acadêmica com maior êxito. Outro fator de destaque é a relação professor - aluno, em que a influência do educador tende a refletir de forma positiva ou negativa no crescimento educacional do aluno, enquanto ser em formação. Com a mudança dos tempos, veio à expansão das instituições de ensino superior, o que facilitou o ingresso de alunos de famílias menos favorecidas economicamente, oportunizando o acesso aos diversos cursos que há tempos atrás não eram possíveis, devido às dificuldades econômicas, de locomoção e permanência longe das famílias. Apesar de todos os empecilhos, é evidente a preocupação de muitas famílias com a escolarização dos filhos e, consequentemente, o seu sucesso escolar, pois nos dias atuais é visível a crise de identidade nas diversas áreas de profissionalização, em que o mercado de trabalho tornou-se, apenas, um campo de competitividade e a escola é considerada como fonte de integração e regeneração do homem na sociedade. Dessa forma, vimos a grande importância da relação escola, família e sociedade como propulsora da relação ensino-aprendizagem escolar.
\end{abstract}

Palavras chave: Relação escola-família-sociedade; Afetividade; Desempenho escolar.

\section{CONTRIBUTIONS ABOUT THE SCHOOL, FAMILY AND SOCIETY RELATIONSHIP IN THE SCHOOL FORMATION PROCESS}

\begin{abstract}
Based on the reading and discussion of the authors of texts such as: Antunes (2007), Borges and Fontoura (2010), Matsuoka (2013), Nogueira (2010), Novoa (1996) Szymanski (2004), they favored a about reflection the relationship school, family and society in the context of guided these relationships as guiding the construction of autonomy as schooling and path taken by the universities. In view of the family as the first social institution in which the child is inserted, it is noticeable that the students who have more family support demonstrate an improvement in school performance and, therefore, to enter and remain in the universities, which contributes for an academic training more successful. Another important factor is the teacher - student relationship, in which the influence of the educator tends to reflect positively or negatively on the educational growth of students while being in training. With the changing times, came the expansion of higher education institutions, which facilitated the entry of students from disadvantaged families economically, providing opportunities for
\end{abstract}

\footnotetext{
${ }^{1}$ Graduanda do Curso de Pedagogia/UAE/CFP/UFCG 
access to the various courses that long ago were not possible due to economic difficulties, mobility and stay away from their families. Despite all the obstacles, it is clear the concern of many families with the education of children and consequently their school success, because nowadays is visible the identity crisis in the various areas of professionalization, in which the labor market has If only a competitive field and the school is considered as a source of integration and regeneration of man in society. Thus, we saw the great importance of school relationship, family and society as a driving school teaching-learning relationship.

Keywords: Relationship school-family-society; affectivity; School performance.

\section{INTRODUÇÃO}

O presente artigo tem por objetivo compreender a relação escola, família e sociedade mediante o processo de escolarização até o ingresso no ensino superior tendo como fonte de referência autores como: Antunes (2007), Borges e Fontoura (2010), Matsuoka (2013), Nogueira (2010), Nóvoa (1996), Szymanski (2004), gerando discussões acerca das perspectivas e desafios enfrentados pelos estudantes para o alcance do sucesso escolar.

Ao considerar a família como a primeira instituição social, em que a criança recebe a primeira educação. De acordo com Szymanski (2004, p.4), “[...] o processo de socialização se dá no convívio familiar e, em especial, por meio das práticas educativas desenvolvidas com a finalidade de transmitir hábitos, valores, crenças e conhecimentos”. A importância do papel da família na formação educativa e inserção social possibilitando o convívio social.

De acordo com estudos, o sucesso escolar depende do acompanhamento familiar. A colaboração da família no desenvolvimento das atividades escolares dos filhos demonstra que, apesar de alguns pais não possuírem escolarização suficientes para ajudarem nas tarefas escolares, o esforço e a valorização que destinam a educação como sendo o principal meio necessário de ascensão social torna-se um forte incentivo para os filhos. Muitos não possuem, economicamente, condições para manter os filhos em escolas privadas, entendendo que a educação pública é o único caminho para adentrar o ensino superior e obter êxito no mercado de trabalho.

Esse estudo surgiu a partir dos problemas enfrentados por muitos estudantes de graduação durante seu egresso e permanência nas universidades. Destacam-se as dificuldades apontadas desde o distanciamento familiar até o mundo acadêmico. Durante o percurso trilhado por estes alunos até chegar ao ensino superior, advindos de escolas públicas apontam

RPI Revista de Pesquisa Interdisciplinar, Cajazeiras, v. 1, Ed. Especial, 145 - 152, set/dez. de 2016. 
o apoio familiar como eixo primordial para o sucesso escolar, a afetividade e o diálogo são os principais aspectos para essa trajetória.

A busca pelo sucesso escolar leva muitos alunos a enfrentar dificuldades dentro do ambiente acadêmico, em muitos casos devido à defasagem de aprendizagem na educação básica. Quando se deparam com o estudo das teorias das ciências da educação, percebem a complexidade. As universidades públicas propõem a inserção em projetos, a fim de contribuir com a facilitação e integração no contexto profissional.

Um dos programas de maior destaque nas universidades públicas é o Programa Institucional de Bolsas de Iniciação a Docência (PIBID), mantido pela Coordenação de Aperfeiçoamento de Pessoal de Ensino Superior (CAPES), contribuindo para o crescimento do estudante de graduação através da iniciação no ambiente de trabalho e colaboração com construção da identidade profissional através da reflexão teoria e prática.

\section{Relação família, escola e sociedade: reflexões iniciais}

Pesquisas revelam que a relação família e escola ainda é um tema muito complexo, conclui-se que a importância de existir uma parceria no desenvolvimento educacional do estudante, o acompanhamento da escolaridade não apenas no ambiente escolar como também no contexto familiar determina de forma eficiente o crescimento do aluno. $\mathrm{O}$ resultado da aprendizagem de alunos que tem o monitoramento dos pais com outros que não tem, demonstra a medida do compromisso da família na formação dos filhos.

De acordo com Nogueira (2010, p. 67) o acompanhamento familiar e a imposição da ordem moral doméstica são fundamentais, “[...] suficientemente forte para balizar os procedimentos sociais", contribui com a formação do filho, na direção do sucesso escolar, a educação é para a vida toda, uma aprendizagem a contemplar todo o processo de formação enquanto ser social.

O reflexo do sucesso escolar depende principalmente das relações construídas a partir do ambiente escolar e da valorização de conceitos moral, reflete no ambiente escolar e mais adiante no ingresso das universidades. Conforme Nogueira $(2010$, p.68) “[...] essa disposição parece ser uma herança proveniente de gerações anteriores que, diante de circunstâncias favorecedoras, como oferta escolar de qualidade mínima, pode se realizar." O sucesso escolar não depende de classe social mais ou menos favorecida, mas da construção das relações dentro da família e a importância que os pais direcionam ao trabalho escolar dos filhos.

RPI Revista de Pesquisa Interdisciplinar, Cajazeiras, v. 1, Ed. Especial, 145 - 152, set/dez. de 2016. 
Algumas atitudes dos pais se tornam relevantes para o sucesso escolar dos filhos, a falta de negligência é um dos fatores determinantes para que muitos alunos sejam destaques na escolarização. Nogueira (2010, p. 68) enfatiza que “[...] a disponibilidade em escutar, ouvir e dar atenção ao filho, permitir que ele dê conta de suas tarefas e necessidades escolares, indagar do seu dia escolar", são ações que influencia o desejo de realização das atividades com mais satisfação.

De acordo com Nogueira (2010) o sucesso de muitos alunos nas universidades é resultado da presença da família. A maioria de classe menos favorecidas, com dificuldades financeiras, demonstram a importância depositada na escolarização dos filhos, que ingressaram em escolas públicas, e que encontra na presença familiar o apoio para conseguir adentrar as universidades e o efeito disto, são alunos com desempenhos excelentes utilizam a sua história como exemplo para incentivar outros a adquirirem o sucesso e construírem uma nova visão acerca da atuação afetiva familiar como principal elo entre escola e a família.

Estudos apontam que além da presença familiar, outros fatores contribuem para o desempenho escolar que é a relação professor-aluno e as representações sociais. A interação entre o educador e o educando pode influenciar de forma positiva ou negativa, o favorecimento ou desfavorecimento escolar. O professor como uma figura determinante para a formação de um ser humano, interfere tanto na transformação comportamental, quanto na construção da autonomia.

Nóvoa (1996) enfatiza que a escola é conceituada como um ambiente propício a aprendizagem, a socialização, a formação e construção de identidades. Para os estudantes de graduação o momento do estágio supervisionado é um momento impar para vivenciar a teoria e a prática. As relações construídas no ambiente escolar são determinantes para a sua profissionalização, as experiências são decisivas para a construção da sua identidade profissional.

Na perspectiva de Matsuoka (2013) a relação construída com a docência compartilhada oportunizada durante a execução dos projetos de cursos no PIBID, integração da universidade e escola, é outro momento contribuinte para a construção da identidade profissional docente mediante o contato com professores, alunos e comunidade escolar. O objetivo principal é a inserção do estudante de graduação no ambiente escolar, cooperando com a construção das relações entre a escola, família e a comunidade.

RPI Revista de Pesquisa Interdisciplinar, Cajazeiras, v. 1, Ed. Especial, 145 - 152, set/dez. de 2016. 
De acordo com Antunes (2007, p.26), “[...] o conhecimento em uma visão atual resulta da interação entre o indivíduo, a informação que lhe é exterior e o significado que este lhe atribui." A aprendizagem adquirida no momento da prática, é impactante para a construção identitária, o conhecimento teórico e as experiências adquiridas durante esse processo transformador, ressignifica e constrói conceitos.

Para Antunes (2007), “[...] aprender é um processo que se inicia a partir do confronto entre a realidade objetiva e os diferentes significados que cada pessoa constrói acerca dessa realidade", compreende-se que as relações sociais são principais ferramentas para aquisição de saberes, desenvolvimento e prática de ações individuais e coletivas.

Nessa perspectiva, a relação desenvolvida entre o estudante de graduação no ambiente escolar favorece sempre uma reflexão critica e auto-avaliativa sobre a construção da identidade profissional, permitindo reavaliar que profissional deseja ser, a integração entre teoria e a prática como necessárias para aprender e apreender o oficio.

Antunes (2007, p.29), diz que “[...] a instrução é essencial ao homem quanto mais instruídos somos, melhor agimos", e o ser humano é construído a partir dessa ligação com o outro, vivenciando e compartilhando saberes. Ainda referencia que a família é considerada um espaço educativo por excelência, detentora de funções que consideramos primordiais para o desenvolvimento da criança, como sendo, social, cultural e biológico. Seu papel é muito importante na relação educativa, a função da família na participação da vida escolar tem sido na maioria dos casos esquecida por outras instituições.

Szymanski (2004) compreende que a família deve ser um objeto de atenção psicoeducacional, forte apoio para o desempenho da função educativa que lhe foi delegada. Assim a pscicoeducação deve tratar da intervenção e orientação a família para que seu papel seja executado na participação da vida escolar.

De acordo com Szymanski (2004) o processo de socialização, acontece por meio das práticas educativas, favorecendo um melhor convívio familiar e a inserção dos filhos na sociedade, contribuindo com ações que desenvolvem a compreensão de valores, crenças e conhecimentos para a convivência com o outro, mostrando a importância de socialização.

Segundo Durning (1999 apud Szymanski 2004, p. 13), “[...] propõe a consideração de dois elementos construtivos do processo educativo na família: os valores dos pais e os aspectos cognitivos", podem ser de ordem moral e de ordem de desenvolvimento de competências. Os processos extrafamiliares influenciam diretamente nos intrafamiliares, se RPI Revista de Pesquisa Interdisciplinar, Cajazeiras, v. 1, Ed. Especial, 145 - 152, set/dez. de 2016. 
fazendo necessário incluir essa questão nos programas de assistência as famílias. Um dos fatores presentes nessa relação é a pobreza, agravante no desenvolvimento humano, pelo fato de comprometer a orientação sistemática voltada para os filhos, assim como os fatores psicológicos resultantes de frustrações e a própria dificuldade econômica em si.

A família contribui na construção de saberes, a partir de práticas educativas resultantes de uma aprendizagem social difundida de geração para geração, objetivando preparar as novas gerações para atuar de forma crítica e ativa na sociedade. Durning (1999 apud Szymanski 2004, p. 13) diz que,

Para a realização dessa tarefa, algumas condições se fazem necessária: um olhar para a criança como sujeito de ação educativa, reconhecimento do status de educadores por parte dos pais e a proposta de desenvolver uma atividade familiar por um período de tempo que corresponda ao de desenvolvimento e amadurecimento dos filhos.

Ainda nessa perspectiva, o sentido de integrar a família em um arranjo social, atende a interesses mais amplos da sociedade e da cultura, a ideia que a desigualdade social tem sido causa de degradação moral, faz parte do conjunto da reestruturação da sociedade.

No contexto de desenvolvimento familiar, a criança precisa de segurança, afetividade e compreensão, para o sentido de existência. Szymanski (2004) diz que as transformações individuais e coletivas são maturadas e podem se desenvolver nos padrões da sociedade em que se vive. É neste meio que a assimilação de valores, hábitos definem diferentes maneiras de trocas com o mundo. A aprendizagem é um processo que está ligado com o desenvolvimento da pessoa, tem relação com trocas intersubjetivas que vão consolidando e afirmando a posição dentro da sociedade, considerando os aspectos sociais e educacionais do desenvolvimento da criança.

A ligação emocional que os membros da família têm uns em relação aos outros, Szymanski (2004, p. 11) relaciona que “[...] as famílias constroem temas dominantes que definem experiências, significados e interações, resultando em um Impacto no Desenvolvimento das Crianças e Adolescentes", compreendido como expressão de cuidado e diferentes condições do modo de proceder entre os membros do grupo familiar. A presença dos pais na escola proporciona um maior suporte ao aluno que também aprende a valorizar o âmbito escolar e os profissionais através de realização das atividades de resgate aos valores 
como: respeito, afetividade, solidariedade, humanização, responsabilidade e sensibilidade com o bem comum.

\section{Considerações Finais}

As relações entre família escola e sociedade no processo de formação escolar exercem um papel fundamental no desenvolvimento educacional do estudante, demonstra que o efetivo acompanhamento dos pais e responsáveis favorece o sucesso escolar desde a educação básica até o ensino superior, resultando da eficiência no desempenho profissional.

A família e a instituição escolar compartilham a mesma função educacional, embora uma não possa fazer o papel da outra. Nos tempos atuais, as responsabilidades dos pais é alvo de discussões entre escola e demais setores da sociedade. Alguns itens são elencados com referência aos modelos de ensino e aprendizagem, o acompanhamento e sustentação emocional da criança ou adolescente apresentam a falta de maturidade para enfrentar as dificuldades sem a presença e os limites colocados pelo adulto.

A dificuldade de aprendizagem de uma criança, ou um adolescente, pode representar sintomas e manifestação da falta e precariedade dos vínculos familiares. Educar não é uma tarefa tão simples e requer meios de integração e socialização no convívio escolar, como também se faz necessário auxiliar e realizar ações que possam influenciar a família no processo de aprendizagem.

As discussões relativas à relação escola, família e sociedade, levam a uma compreensão de que apesar das dificuldades enfrentadas pelas famílias para manter os filhos na escola, ainda veem na educação um meio de alcançar a ascensão social, um futuro a ser assegurado e a oportunidade de ingresso no ensino superior e consequentemente atender a demanda do mercado de trabalho.

\section{REFERENCIAS}

ANTUNES, Celso. Professores e professauros: reflexões sobre a aula e práticas pedagógicas diversas/ Celso Antunes, - Petrópoles, RJ: Vozes, 2007.

BORGES, Luíz Paulo Cruz. FONTOURA, Helena Amaral. Diálogos entre a escola de educação básica e a universidade: a circularidade de saberes na formação docente.

RPI Revista de Pesquisa Interdisciplinar, Cajazeiras, v. 1, Ed. Especial, 145 - 152, set/dez. de 2016. 
Rev. do programa de Pós-graduação em educação, Campo Grande, MS, v. 16. n. 32, p. 143-156, jul./dez. 2010.

NOGUEIRA, Maria Alice. Família e escola: Trajetórias de escolarização em camadas médias e populares. (Orgs.) Geraldo Romanelli, Nadir Zago. 5. Ed. Petrópolis, RJ: Vozes, 2010.

NÒVOA. Antônio, Relação Escola/Sociedade: novas respostas para um velho problema. UNIVESP III, Congresso Estadual Paulista sobre a formação de professores. Águas de São Pedro 22 de maio de 1996.

MATSUOKA, Silvia. Integração universidade e escola pelo Pibid: uma análise das ações formativas de supervisores aos licenciandos. Revista Veras, São Paulo, v.3, n.2, p.145-159, julho/dezembro/2013.

SZYMANSKI, Heloisa. Práticas educativas familiares: A família como foco de atenção psicoeducacional. Rev. Estudos de psicologia, PUC Campinas, v. 21, n.2, p. 5-16, maio/agosto 2004 . 